\title{
EDUCAÇÃO INTERPROFISSIONAL E OS DESAFIOS PARA A FORMAÇÃO DOCENTE EM SAÚDE: O CASO DA FACULDADE DE CEILÂNDIA/UNIVERSIDADE DE BRASÍLIA
}

\author{
Clélia Maria de Sousa Ferreira Parreira ${ }^{1}$ \\ Antônio de Pádua Pithon Cyrino ${ }^{2}$ \\ Patrícia Maria Fonseca Escalda ${ }^{3}$
}

\section{INTRODUÇÃO}

O ensino superior no Brasil, de uma forma geral, e a formação de profissionais de saúde, em especial, passa por significativas mudanças. Nesse processo, é possível destacar dois indutores importantes: a instituição do Programa de Apoio a Planos de Reestruturação e Expansão das Universidades Federais (REUNI), por meio da publicação do Decreto Presidencial ํㅜ 6.096, de 24 de abril de 2007, e a aprovação pelo Conselho Nacional de Educação, a partir de 2001, de novas Diretrizes Curriculares Nacionais para as diversas profissões da saúde. Estas diretrizes curriculares nacionais passam a exigir que durante a formação destes profissionais haja o desenvolvimento de novas competências e habilidades. As quais, para que sejam alcançadas, têm demandado das Instituições de Ensino Superior (IES) a reorganização dos cursos, a elaboração (ou atualização) dos projetos político-pedagógicos, assim como a revisão das metodologias e tecnologias de ensino-aprendizagem empregadas. Todavia, para que tais iniciativas sejam efetivamente implementadas tem se mostrado essencial o desenvolvimento de programa de formação docente orientado para os objetivos político-pedagógicos requeridos neste processo de mudança. Esta formação pedagógica é estratégica para que o corpo docente possa participar da construção e fortalecimento de sua identidade profissional, bem como reconhecer e superar algumas "ilusões" que marcam o ideário docente quanto ao ensino superior (PIMENTA, 2012), quais sejam:

\footnotetext{
1 Faculdade de Ceilândia da Universidade de Brasília (FCE/UnB). Endereço eletrônico: cleliaparreira@unb.br.

${ }^{2}$ Faculdade de Medicina da Universidade Estadual Paulista (Unesp/Botucatu). Endereço eletrônico: acyrino@gmail.com.

3 Faculdade de Ceilândia da Universidade de Brasília (FCE/UnB). Endereço eletrônico: escalda@unb.br.
} 
(1) a ideia de que o fundamento pedagógico está no saber disciplinar; (2) que a despeito do conteúdo a ser tratado o domínio didático é o suficiente; (3) que a competência para a pesquisa é o bastante para uma boa docência; (4) que saber manejar uma turma, uma classe, o qualifica; (5) e, que os saberes sobre educação geram os saberes pedagógicos.

Além dessas ilusões destacadas, no caso específico da docência universitária, existem mitos que precisam ser enfrentados, conforme nos alerta Pimenta e Anastasiou (2014): - o de considerar que a oferta de disciplinas pedagógicas é suficiente para responder à necessidade de preparação do professor universitário para a docência; e de considerar os campos da Pedagogia e da Didática como sendo relacionados exclusivamente à aprendizagem de crianças e adolescentes, reduzindo, portanto, sua importância nos demais espaços formativos; e o de entender a Didática como um campo disciplinar em conflito ou competição com os demais. Para esclarecimento a esse respeito, tais autores fazem uma diferenciação necessária que coloca o pedagógico relacionado às finalidades da educação, cujos objetivos políticos e sociais exigem formas organizativas e metodológicas próprias, e o ensino como sendo o campo da Didática, no qual ela mesma, de forma sintética, se constitui uma das áreas da Pedagogia.

Se houve, e se têm elementos suficientes para afirmá-lo, uma complexificação da educação é natural que o mesmo tenha ocorrido com a prática docente e, consequentemente, a sua profissionalização. Nesse sentido, a formação docente passa a assumir novo papel, ao qual são acrescidas renovadas perspectivas de ensino-aprendizagem, de participação social, de reflexão e de enfrentamento e adaptações a um mundo em transformação e dotado de incertezas. Pimenta (2012) enfatiza que nas práticas docentes e nos saberes pedagógicos estão contidos inúmeros outros elementos relacionados à problematização, intencionalidade, experimentação metodológica e didática inovadora; ao enfrentamento de situação complexas, à memória e à própria pesquisa como princípio formativo na docência.

\section{A FORMAÇÃO DOCENTE PARA A INOVAÇÃO}

A criação da Faculdade de Ceilândia na Universidade de Brasília (FCE/UnB) abriu novas oportunidades formativas extremamente favoráveis à 
reflexão e o aprofundamento das questões pedagógicas implicadas no cotidiano docente. Os cursos de graduação da FCE/UnB - Enfermagem, Farmácia, Fisioterapia, Fonoaudiologia, Saúde Coletiva e Terapia Ocupacional - tiveram início após a aprovação das novas Diretrizes Curriculares Nacionais (DCN) para a formação em saúde e refletem, em seus projetos políticos-pedagógicos e desenhos curriculares, uma proposta de trabalho que requer, por parte de todos os membros da comunidade acadêmica, a instituição de espaços próprios e permanentes de discussão acerca das questões imbricadas na implementação de sua identidade acadêmica frente às orientações atuais para formação de novos profissionais no campo da saúde.

A inexistência de estrutura departamental na FCE/UnB, substituída por instâncias colegiadas de gestão universitária, tem favorecido a formação docente, uma vez que as discussões passam a ocorrer de forma mais estratégica e ampliada, incidindo em maior qualificação dos professores, que complementam as ações de formação docente específicas. Tais ações que têm sido organizadas semestralmente visam à atualização pedagógica dos docentes no tocante às abordagens problematizadoras e sua maior adequação ao desenho formativo interprofissional. De uma forma geral, a proposta de formação docente tem sido organizada mediante a realização de dois tipos de atividades: 1) encontros temáticos, com a participação de especialistas convidados, com os quais são debatidos os temas mais abrangentes e permitem uma primeira aproximação com as abordagens problematizadoras; e 2) oficinas, nas quais os participantes podem vivenciar as metodologias problematizadoras e experimentar sua aplicação nas ementas, programas e demais atividades acadêmicas pelas quais respondem, nos diferentes cursos.

Dentre as temáticas já abordadas, destacam-se: a) as novas diretrizes curriculares para a formação dos profissionais de saúde e o Sistema Único de Saúde (SUS); b) as experiências de revisão e organização curricular e de novas práticas docentes no contexto da formação dos profissionais em saúde; c) os fundamentos teóricos e metodológicos das abordagens problematizadoras e suas implicações na prática docente; e, ainda, d) a integração das práticas docentes, dedicada à vivência de metodologias ativas com vistas à instrumentação dos docentes para efetuarem o aperfeiçoamento, as adaptações ou ajustes necessários em suas propostas de ensino que pudessem incidir sobre um maior 
desenvolvimento e aprendizagem do corpo discente e para uma efetiva integração acadêmica.

Será sobre esta experiência de formação docente na FCE/UnB que 0 presente texto busca analisá-la à luz da literatura específica desta área de formação e, também, da que trata da interprofissionalidade. Dado o caráter ainda bastante novo da educação interprofissional entre nós, a formação docente assume uma grande relevância.

\section{SOBRE A FORMAÇÃO DOCENTE}

Dado que os saberes da docência se constituem na medida em que os professores recorrem à sua própria experiência, aos conhecimentos que trazem de sua área específica e os articulam com aqueles construídos pela pedagogia, mais especificamente pela didática, a formação e os saberes docentes qualificam a prática pedagógica do professor e contribuem para o desenvolvimento de sua identidade profissional. Espera-se que os professores, no cotidiano do seu trabalho, façam convergir tais saberes e recorram aos repertórios que foram adquiridos no exercício da própria docência. Com isto, nossa expectativa é que esse movimento resulte em maior qualificação para o ensino.

Tais questões e sua relevância ganham maior expressão no campo da saúde, no qual predominam os saberes próprios das áreas nas quais os docentes foram originalmente formados e no qual há uma declarada ausência de formação específica para a docência (CASTANHO, 2012; ALBUQUERQUE, STOTZ, 2004), ainda que este problemas não se limite a Saúde (PIMENTA e ANASTASIOU, 2014).

A formação docente tem um caráter de autoformação que envolve minimamente três processos: 1) desenvolvimento pessoal (produção da vida do professor); 2) desenvolvimento profissional (produção da profissão docente); e, 3) desenvolvimento organizacional (produção da instituição de ensino no qual o professor está situado), sendo tais elementos processuais fundamentais e influentes na qualidade do próprio trabalho docente. No entanto, este trabalho- que passa a ser visto como tal a partir da sua profissionalização, e não apartado da própria concepção de trabalho - demanda uma análise que situe o professor do ponto de vista social e o defina como responsável pela ação que depreende na intenção das transformações sociais necessárias. Trata-se, pois, conforme argumenta Azzi 
(2012), de um trabalho "inteiro" que expressa a síntese de um saber que é pedagógico e que se constrói no cotidiano de suas práxis.

A profissão docente requer um preparo que, para além de proporcionar um conhecimento válido, possa gerar uma atitude interativa, dialética e vigorosa de valorização e compromisso com as transformações sociais, o que requer à criação de estratégias e métodos de intervenção e de cooperação tanto internamente ao contexto organizacional, quanto profissional e social (IMBERNÓN, 2011). Trata-se de um ofício ou profissão classificado como sendo de relações humanas (ou de trabalho imaterial) que, como tal, aponta e lida com questões de poder e de valor (TARDIF e LESSARD, 2014).

É, conforme argumenta Tarif (2014), um trabalho que tem um aspecto artesanal, cujo processo pede a elaboração de seus instrumentos, bem como a construção e reconstrução de locais e espaços de trabalho, desde uma perspectiva subjetiva do próprio trabalhador e que - como as demais práticas profissionais que envolvem emoções - suscita questionamentos acerca das intenções, dos valores e da maneira de ensinar, de entrar em relação, sobre as consequências de determinadas práticas e sobre as bases e convicções a partir das quais o professor se apoia. A docência, desde essa perspectiva, não se configura ocupação secundária com relação à hegemonia do trabalho material; mas "uma das chaves para a compreensão das transformações atuais das sociedades do trabalho" (TARDIF, 2014, p. 17), uma vez que a profissão docente - por estar fortemente relacionada ao crescimento dos conhecimentos formais, das informações abstratas e das tecnologias, e por ter nos seres humanos seu objeto de trabalho - passa a ganhar maior visibilidade, além de passar a exigir uma formação longa e de alto nível, apesar de ainda não haver alcançado a valorização social que lhe é correspondente ou que dela tem sido esperada. Trata-se de um trabalho cuja especificidade requer uma qualificação que ultrapassa a noção de habilidades instrumentais ou destreza para o manejo de sala. Dado que, em suas mãos também repousam a expectativa da valorização do ensino, a democratização das instituições formadoras, de um ensino de qualidade, que supere a polarização posta entre execução e formulação, dentre tantas outras que se apresentam no âmbito de outras profissões. Nesse sentido, a aquisição de conhecimentos por parte do professor traz características de natureza complexa, adaptativa e experiencial. 
Mas há, de forma imbricada ao saber profissional docente, uma identidade que precisa ser construída: a identidade docente. Ainda que a questão da identidade profissional nos remeta a um processo marcadamente dinâmico e ao fato dela se constituir como prática social, alguns fatores têm sido referidos como sendo seus elementos fundamentais. Trata-se da significação social que a profissão docente tem alcançado e os significados que o próprio professor the tem conferido (PIMENTA, 2012).

No caso específico da profissão docente existe um elemento que the dá complexidade. Todos os professores, independentemente da área na qual lecionam, tiveram mais de quinze anos de escolarização, acumulando, portanto, experiência educativa que the permite estabelecer padrões de excelência ou de incompetência docente, tendo exclusivamente como parâmetro para essa avaliação a sua visão e vivência como estudante. Resultado disso tem sido o fato de muitos professores não se identificarem como tal, e sequer perceberem que o ingresso nessa nova profissão demandará saberes para os quais sua formação original não o tenham preparado. As necessidades pedagógicas com as quais os docentes lidam em seu cotidiano de trabalho superam os eventuais e apriorísticos esquemas e sistemas formativos aos quais possam haver sido submetidos.

Embora a profissão de professor tenha emergido, como todas as outras, em dado contexto histórico e social, o que Ihe conferiu legalidade, a construção de sua identidade passa por um período de profunda reflexão.

Nesse momento, se tem trazido para o debate a identidade profissional do professor como reconhecendo a docência como um campo de conhecimentos que reúne conteúdos de diversas áreas do saber e do ensino. Por dizer respeito à humanização, a educação se vincula aos processos civilizatórios, fortemente marcados por transformações sociais, o que faz com que a formação para a docência se complexifique e passe a demandar a proposição de programas e ações voltadas à formação docente em que os próprios docentes, como defende Nóvoa (2009), tenham lugar predominante na formação de seus pares, de forma tal que sejam produzidos novos modelos de organização da profissão, nos quais eles mesmos possam ser seus principais responsáveis. Ainda de acordo com este autor, os movimentos pedagógicos ambientados em comunidades de prática tendem a reforçar o sentimento de pertença e a consolidar a identidade profissional docente, cuja autonomia e visibilidade social precisam ser reafirmadas. Nesse sentido, o 
conceito de comunidade de prática, trazido por Wenger $(1998,2003)$, pode ser adotado, especialmente por referir-se à aprendizagem do adulto, que se dá no universo da colaboração, da ação cooperada, do engajamento mútuo e do empreendimento; da aprendizagem contextualizada na prática; da identidade compartilhada e da negociação de significados, o que traz tensões.

No entanto, Nóvoa e Amante (2015) afirmam que atualmente a profissão acadêmica e o ensino têm sido sistematicamente relegados a um segundo plano, a despeito de sua defesa no âmbito discursivo, posto que se aprende a ser professor "por intuição, usando a experiência de quando se foi aluno e reproduzindo práticas desajustadas da realidade actual", muito em função de a universidade, ao tratar de sua modernização, "ignorar a pedagogia, como se esta fosse inata ou, mesmo, supérflua e desnecessária" (p. 26).

Situação análoga é destacada por pesquisadores brasileiros quando, ao discutirem sobre o ensino na saúde no Brasil, apontam para uma hierarquia na qual a pesquisa se sobrepõe à docência, o que pode acentuar um recorte ou viés quanto à qualificação e ao reconhecimento do trabalho docente, a despeito dos conteúdos ou das especificidades com as quais lidam, uma vez que para além da "falta de formação do docente e da percepção do contexto político do seu trabalho", as questões tidas como centrais no trabalho do docente nas universidades seguem a ordem de que ele deva ser "um bom investigador, obter recursos para sua pesquisa, publicar em periódico de prestígio na área e dar algumas aulas na graduação ou na pós-graduação" (CYRINO et al, 2015, p. 143)

Mas, os saberes da experiência docente são componentes da prática do professor que têm maior relação com a formação profissional, o que inclui as disciplinas, o currículo e a tradição pedagógica (CUNHA, 2007) e desconsiderar a dimensão epistemológica da pedagogia, que define seu campo científico e profissional, finda por reduzi-la à sua expressão metodológica e procedimental, o que compromete o entendimento e a própria construção da identidade profissional docente em que, se desprovida de conteúdos e métodos próprios de produção de saberes, "a pedagogia facilmente se converte em tecnologia, em modo de fazer, em fazeres práticos" (LIBÂNEO, 2006, p.870), sendo que são os saberes pedagógicos que dão suporte aos saberes disciplinares, qualificando a ação docente e deles exigindo a capacidade de articular o aparato teórico-prático e de mobilizá-lo rumo à organização e à produção de novos saberes, a partir de sua própria prática. 
A dimensão educativa do trabalho do professor está diretamente relacionada à sua capacidade de conduzir processos que envolvem conhecimentos, para além dos seus próprios, e à humanização do processo educativo (RODRIGUES, 2001; LIBÂNEO, 2006; LIBÂNEO \& PIMENTA, 1999). Nesse sentido, a formação docente de professores universitários, sobretudo os da saúde, precisam considerar dois movimentos destacados por Nóvoa (2009): - o primeiro movimento, entre a pedagogia e as profissões, cuja ligação é considerada evidente e existe há longa data, como é o caso dos cursos de medicina, que têm lugar em Faculdades dentro dos Hospitais, o que contribui para o estabelecimento de uma relação direta entre formação e profissão, desde uma perspectiva de associação entre o mundo universitário e o mundo do trabalho; e o segundo movimento, entre a pedagogia e a sociedade, cuja ligação conecta a universidade às grandes questões da sociedade, que se fazem presentes no trabalho acadêmico e pedagógico.

Tardif (2014) enfatiza as características que precisam ser reafirmadas no tocante aos saberes profissionais: 1) eles serem temporais, por terem como bagagem conhecimentos, crenças, representações e certezas acumuladas nos anos vividos durante suas trajetórias escolares que, mesmo sendo anteriores à prática profissional docente, se tornam fortes e presentes no seu cotidiano de trabalho; 2) eles serem plurais e heterogêneos, por reunirem cultura pessoal, conhecimentos disciplinares e aqueles resultantes do próprio ofício de professor; e 3) eles serem personalizados e situados, por integrarem sistemas cognitivos e histórias de vida, que comportam saberes que foram apropriados e subjetivados e, por consequência, são singulares.

No entanto, para que se possa avançar na proposição ou consolidação de propostas ou programas de formação docente que levem em conta o componente prático do trabalho docente, se faz necessário que a sua realização seja feita a partir dos saberes da própria profissão, considerando a aquisição da cultura profissional docente, assegurando aos professores mais experientes o papel estruturante na formação dos mais novos; que a necessidade da dedicação especial às dimensões subjetivas implicadas na profissão docente, fortalecendo a capacidade relacional e de comunicação necessárias à prática profissional não seja negligenciada; e que a valorização do trabalho em equipe e o exercício coletivo da profissão, com destaque para o princípio da responsabilidade social sejam assegurados como parte do processo formativo (NÓVOA, 2009). 


\section{FORMAÇÃO DOCENTE NA ÁREA DA SAÚDE E A EDUCAÇÃO INTERPROFISSIONAL}

A docência, como outras profissões, lida com seres humanos. No entanto, diferentemente do que ocorre com diversas outras profissões, essa relação modifica a própria natureza do trabalho e a atividade do trabalhador. Essa afirmação é relevante por revelar que o trabalho sobre e com seres humanos evidencia a humanidade em todos os seus processos e vincula o trabalhador, uma vez que em qualquer "ocupação, arte ou ciência, ofício ou profissão, a relação do trabalhador com o seu objeto de trabalho e a própria natureza desse objeto são essenciais para se compreender a atividade em questão" (TARDIF, 2014, p. 31).

A formação docente na área da saúde implica muito diretamente no estabelecimento de uma comunicação entre sujeitos, em que o diálogo que se estabelece, acrescenta o rastro histórico no qual a linguagem é apenas uma parte, em que cada sujeito dialoga também com o seu "auditório social" (DONATO \& ROSENBURG, 2003). Embora o docente da área da saúde insista em considerar seu conhecimento clínico específico suficiente para assegurar-lhe uma boa prática docente e em desconsiderar o objeto da pedagogia e a importância dos processos de mediação como dizendo respeito à sua ação profissional, quando se fala na identidade docente de profissionais na área da saúde, há uma reafirmada consideração à imensa bagagem que os professores trazem de suas áreas originais. Ainda que sem fazer referência específica aos professores universitários de uma área específica, Pimenta e Anastasiou (2014) enfatizam que as próprias instituições que os selecionam dão por suposto que os professores possuem formação docente e se desobrigam de ofertá-la, o que resulta em uma situação em se pode encontrar professores no ensino superior que sem qualquer processo formativo, sequer sem terem escolhido a profissão docente, entendam como natural a sua passagem para a docência. Para aqueles que atuam em áreas específicas - afirmam essas autoras, e o que se pode aplicar à docência na área da saúde - a profissão docente "passa a ser também sua carreira; embora muitas vezes a instituições de ensino superior e o próprio profissional professor não atentem para isso" (p.106).

No caso da saúde, a formação profissional tem se fundamentado historicamente em uma visão disciplinar, muito focalizada na Biomedicina. No entanto, a complexidade dos problemas de saúde tem exigindo mudanças neste 
paradigma dominante e tem evidenciado a necessidade de reorientação do modelo vigente. É consenso que práticas colaborativas entre profissionais de saúde podem oferecer um cuidado mais seguro e efetivo e que nenhum profissional isoladamente é competente o suficiente para materializá-las (MCPHERSON, HEADRICK \& MOSS, 2001; AGUILAR-DA-SILVA, SCAPIN e BATISTA, 2011). As competências necessárias para a promoção da educação interprofissional na graduação e os fatores relacionados às barreiras para a sua vivência e aprendizagem colaborativa no ensino superior são alguns dos desafios enfrentados pelas instituições formadoras com esta orientação político-pedagógico.

Embora o conceito de Educação Interprofissional (IPE) não seja novo (BURING et al, 2009), para pesquisadores e profissionais do setor de saúde há uma falta de clareza a seu respeito. A educação interprofissional se refere à educação "na qual os profissionais de saúde aprendem colaborativamente dentro e através de suas disciplinas, a fim de obter os conhecimentos, habilidades e valores necessários para trabalhar com outros profissionais de saúde" (CIHC, 2007), com o intuito de estimular o "aprimoramento do cuidado em saúde por meio do trabalho de equipe e seus princípios se aplicam tanto para a graduação das diferentes profissões de saúde quanto para a educação permanente dos profissionais componentes de uma equipe de trabalho" (WHO, 2010, p.26).

A literatura internacional tem sinalizado para o fato de que se grupos de estudantes e de profissionais de saúde tiverem oportunidades para estarem juntos, eles tenderão a se tornarem conscientes das capacidades e das competências uns dos outros e a desenvolverem práticas mais colaborativas (KHALILI et al, 2013; OANDASAN \& REEVES, 2005; DARLOW et al, 2015; MILBURN \& COLYER, 2008; REEVES et al, 2013; WHO, 2010; BARR et al, 2005; BARR e LOW, 2012; MCPHERSON, HEADRICK \& MOSS, 2001; HAMMICK et al, 2008).

Para Milburn \& Colyer (2008), a educação interprofissional envolve diferentes grupos profissionais na aprendizagem interativa para o desenvolvimento de habilidades como comunicação, negociação, resolução de problemas, trabalho em equipe e gestão de conflitos, enquanto que na aprendizagem compartilhada participantes são atraídos, a partir de dois ou mais grupos profissionais, na qual o ensino e aprendizagem se centra no conteúdo comum do currículo e não necessariamente no desenvolvimento de habilidades de interação. 
Para a Organização Mundial de Saúde (2010) existem evidências suficientes para se afirmar que a educação interprofissional (a) leva à prática colaborativa e que esse tipo de prática; (b) otimiza e fortalece o sistema e os serviços de saúde; (c) melhora os resultados de saúde; (d) melhorar o acesso, a estruturação e a coordenação da assistência; (f) diminuir complicações de saúde dos usuários dos serviços públicos, o tempo de permanência e as internações hospitalares, as taxas de erros clínicos, assim como (g) minimiza a tensão e o conflito entre cuidadores.

Diferentes autores têm destacado uma série de barreiras significativas à educação interprofissional que vão desde as estruturais, causadas e mantidas dentro ou entre sistemas de saúde e de educação, até aquelas que são construídas dentro das culturas profissionais ou relacionadas às diferenças de atitudes frente às práticas colaborativas (BAKER et al, 2011; FEWSTER-THUENTE, 2011; GILBERT, 2005; HALL, 2005; BURING et al, 2009). Tais dificuldades existem ocorrem, mesmo nas experiências em que se fez opção por desenhos mais interprofissionais, como é o caso da FCE/UnB que busca, sistematicamente, investir na formação do seu quadro de professores e criar oportunidades para discussão das práticas docentes e sua aproximação com as orientações metodológicas e as bases conceituais que fundamentaram os projetos pedagógicos dos cursos.

\section{FORMAÇÃO DOCENTE E EDUCAÇÃO INTERPROFISSIONAL: O CASO DA FCE/UNB}

No caso específico da formação docente na Faculdade de Ceilândia, e a despeito das ações formativas realizadas sistematicamente, se observa a persistência de algumas ilusões e certos mitos relacionados à relevância da formação docente, nos termos trazidos pela literatura - principalmente, embora não exclusivamente - por tratar-se de um projeto de características inovadoras e interprofissionais, que exige novos e contínuos momentos de reflexão e de atualização teórica e metodológica.

A FCE/UnB possui um desenho curricular construído coletivamente, sendo marcadamente interdisciplinar, ancorado na relação orgânica entre ensino, pesquisa e extensão, havendo sido fundamentando em uma perspectiva interprofissional. Para a sua consolidação, se tem procurado assegurar que os 
estudantes tenham contato direto e compartilhado acerca de conteúdos, abordagens e situações práticas de articulação ensino-serviço-comunidade com base em quatro eixos estruturantes: 1) Modo de Vida, 2) Sistemas Biológicos, 3) Especificidades do Fazer Profissional, 4) Cenários de Práticas e os Seminários Integrativos, organizados de forma a favorecer o desenvolvimento de habilidades e saberes que levem à práticas mais seguras e colaborativas.

Os seis cursos de graduação na área da saúde nasceram tendo como orientações os princípios e as DCN para a formação em saúde, refletindo em seus projetos políticos-pedagógicos a perspectiva interprofissional como sendo uma de suas maiores características.

Passados cerca de oito anos desde sua criação, e havendo sofrido algumas mudanças sutis nos seus projetos pedagógicos dos cursos, além da agregação de novos docentes que não participaram da construção - mas que se encontram no momento de se apropriarem desses projetos - é chegada a hora de uma avaliação mais ampla, que busque evidências sobre as contribuições das perspectivas inter e transdisciplinar para o desenvolvimento de processos de reflexão acerca da função e do papel docente na produção de conhecimentos centrados no cotidiano profissional e nas experiências orientadas à preparação dos docentes para conduzirem experiências de educação interprofissional. Espaços de convergência entre áreas, saberes e conhecimentos, sobretudo os fronteiriços, sinalizam para melhores práticas e relações entre profissões, cujas especificidades técnicas são complementares. Debater sobre quais transformações a educação interprofissionais traz para a organização e dinâmica de funcionamento dos cursos, assim como identificar barreiras à sua implementação no ensino superior, tem relação direta com a questão da educação e da formação de professores.

\section{CONSIDERAÇÕES FINAIS}

Levando em conta as barreiras que se colocam à formação docente e suas implicações na implementação da educação interprofissional, há necessidade do desenvolvimento de um plano institucional ousado levar a comunidade acadêmica a refletir acerca das implicações das práticas pedagógicas docentes para o exercício, aplicação e aperfeiçoamento de seu desenho curricular interprofissional, 
o que requer, além do monitoramento e avaliação constantes de seus processos de implantação, a criação de espaços e de grupos para a realização de pesquisas sobre ambas temáticas (formação docente e interprofissionalidade); 0 estabelecimento de uma agenda comum, intra e interinstitucional, para o desenvolvimento de estratégias de desconstrução dos mitos e equívocos relacionados à educação interprofissional e a criação de espaços potentes para a realização de discussões interativas e abertas sobre colaboração e ação cooperada em saúde.

\section{REFERÊNCIAS}

AGUILAR-DA-SILVA, R.H., SCAPIN, L.T. e BATISTA, N.A. Avaliação da formação interprofissional no ensino superior em saúde: aspectos da colaboração e do trabalho em equipe. Avaliação, Campinas; Sorocaba/SP, mar., 2011, v. 16, n. 1, p. 167-184

ALBUQUERQUE, P.C.; STOTZ, E.N. A educação popular na atenção básica à saúde no muninípio: em busca da integralidade. Interface - Comunic., Saúde, Educ.,mar/ago, 2004, v.8, n.15, p.259-74.

AZZI, S. Trabalho docente: autonomia didática e construção do saber pedagógico. In: PIMENTA, S.G. (org). Saberes pedagógicos e atividade docente. 9 ed. São Paulo: Cortez, 2012, p. 39-69.

BAKER, L., EGAN-LEE, E., MARTIMIANAKIS, M.A., \& REEVES, S. Relationships of power: implications for interprofessional education. Journal of Interprofessional Care, 2011, 25(2), 98-104.

BARR, H. Competent to collaborate; towards a competency-based model for interprofessional education. Journal of Interprofessional Care, 1998, 12(2):181-8. BARR, H., LOW, H. Interprofessional Education, In: CAIPE. Centre for the Advancement of Interprofessional Education. Pre-registration Courses. A CAIPE Guide for Commissioners and Regulators of Education, 2012.

BATISTA, N.A. Et al. O enfoque problematizador na formação de profissionais da saúde. Interface-Comunic, Saúde, Educ, abr/jun, 2008, v.12, n.25, p.433-41. BURING, S.M.; HUSHAN, A.; BROESEKER, A.; CONWAY, S.; DUNCAN-HEWITT, W.; HANSEN, L.; WESTBERG, S. Interprofessional Education: definitions, student competencies, and guidelines for implementation. American Journal of Pharmaceutical Education, 2009; 73 (4), Article 59.

CASTANHO, M.C. Professores de ensino superior da área da saúde e sua prática pedagógica. Interface-Comunic, Saúde, Educ, 2002, v. 6, n.10, p.51-62. CIHC. Canadian Interprofessional Health Collaborative. A National Interprofessional Competency Framework, 2010. 
DARLOW, B., COLEMAN, K., MCKINLAY, E., DONOVAN, S., BECKINGSALE, L., GRAY, B., NESER, H., PERRY, M., STANLEY, J., \& PULLON, S. The positive impact of interprofessional education: A controlled trial to evaluate a programme for health professional students. BMC Medical Education, 2015, 15 (98), 1-9.

D'AMOUR, D., FERRADA-VIDELA, M., L.S.M. RODRIGUEZ \& BEAULIEU, M. The conceptual basis for interprofessional collaboration: Core concepts and theoretical frameworks. Journal of Interprofessional Care, May, 2005, Supplement 1: 116 131.

D'AMOUR, D. \& OANDASAN , I. Interprofessionality as the field of interprofessional practice and interprofessional education: An emerging concept. Journal of Interprofessional Care, 2005, v. 19, n. 1: 8-20.

DONATO, A.F.; ROSENBURG, C.P. Algumas ideias sobre a relação educação e comunicação no âmbito da Saúde. Saúde soc. 2003, v. 12, n. 2, p. 18-25.

FEWSTER-THUENTE, L.L. (2011). Working Together Toward a Common Goal: A Grounded Theory of Nurse-Physician Collaboration. Dissertations, 2011, Paper 196.

GILBERT, J.H.V. (2005). Interprofessional learning and higher education structural barriers. Journal of Interprofessional Care, May, 2005, Supplement 1: 87-106. HALL, P. Interprofessional teamwork: professional cultures as barriers. Journal of Interprofessional Care, May, 2005, Supplement 1: 188-196.

HAMMICK, M., FREETH, D., KOPPEL, I., REEVES, S. \& BARR, H. A Best Evidence Systematic Review of Interprofessional Education BEME Guide no. 9. Medical Teacher, 2008, v. 29. n. 8: 735-51.

KHALILI, H., ORCHARD, C., LASCHINGER, H.K. S. and FARAH, R. (2013). An interprofessional socialization framework for developing an interprofessional identity among health professions students. Journal of Interprofessional Care, 2013; 27(6): 448-453.

IMBERNÓN, F. Formação docente e profissional: formar-se para a mudança e a incerteza. 9 ed. São Paulo: Cortez, 2011, v. 14 (Coleção questões da nossa época). MCPHERSON ,K; HEADRICK , L., \& MOSS, F. Working and learning together: good quality care depends on it, but how can we achieve it? Quality in Health Care 2001;10 (Suppl. II):46-53.

MILBURN, P.C. \& COLYER, H. Professional knowledge and interprofessional practice. Radiography. 2008, v. 14:318-322.

NÓVOA, A. Para una formación de profesores construida dentro de la profesión. Revista de Educación, 350. Septiembre-diciembre, 2009, p. 203-218.

NÓVOA, A.; AMANTE, L. Em busca da liberdade. A pedagogia universitária do nosso tempo. Revista Docencia Universitaria, enero-abril, 2015, v.13. n,1, p. 21 34. 
OANDASAN, I. \& REEVES, S. Key elements of interprofessional education. Part 2: Factors, processes and outcomes. Journal of Interprofessional Care. May, 2005, Supplement 1: $39-48$.

PEDUZZI, M.; NORMAN I.J.; GERMANI A.C.C.G.; SILVA J.A.M.; SOUZA G.C.

Educação interprofissional: formação de profissionais de saúde para o trabalho em equipe com foco nos usuários. Rev Esc Enferm USP, 2013, v. 47, n. 4, p. 977-83.

PIMENTA, S.G.; ANASTASIOU, L.G.C. Docência no ensino superior. 5a ed. - São Paulo: Cortez, 2014.

PIMENTA, S.G. Saberes pedagógicos e atividade docente. 8a ed. - São Paulo: Cortez, 2012.

REEVES, S., PERRIER, L., GOLDMAN, J., FREETH, D., \& ZWARENSTEIN, M. Interprofessional education: Effects on professional practice and healthcare outcomes (update) (Review). The Cochrane Collaboration. 2013, Issue 3. John Wiley \& Sons, Ltda.

TARDIF, M. Saberes docentes e formação profissional. 17 ed. Petrópolis/RJ: Vozes, 2014.

TARDIF, M.; LESSARD, C. 0 trabalho docente: elementos para uma teoria da docência como profissão de interações humanas. 9a ed. Petrópolis/RJ: Vozes, 2014.

WENGER, E. Communities of practice, learning, meaning and identidy. New York: Cambridge Universitity Press, 1998.

WENGER, E. Communities of practice and social leraning systems. New York: Cambridge Universitity Press, 2003.

WHO. World Health Organization. Framework for action on interprofessional education \& collaborative practice. Geneva: WHO, 2010. 